\title{
Divine forgiveness may improve mental health
}

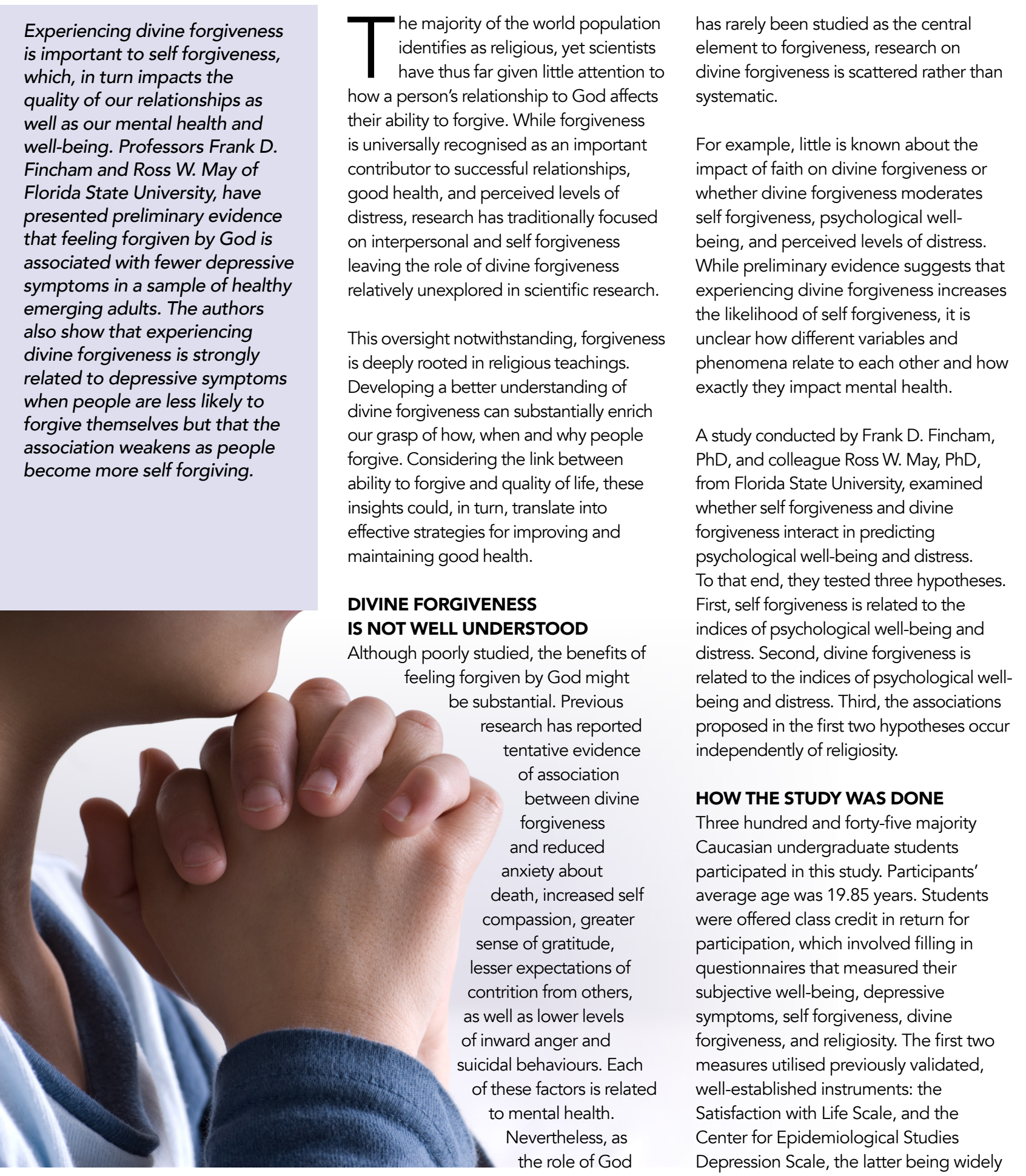

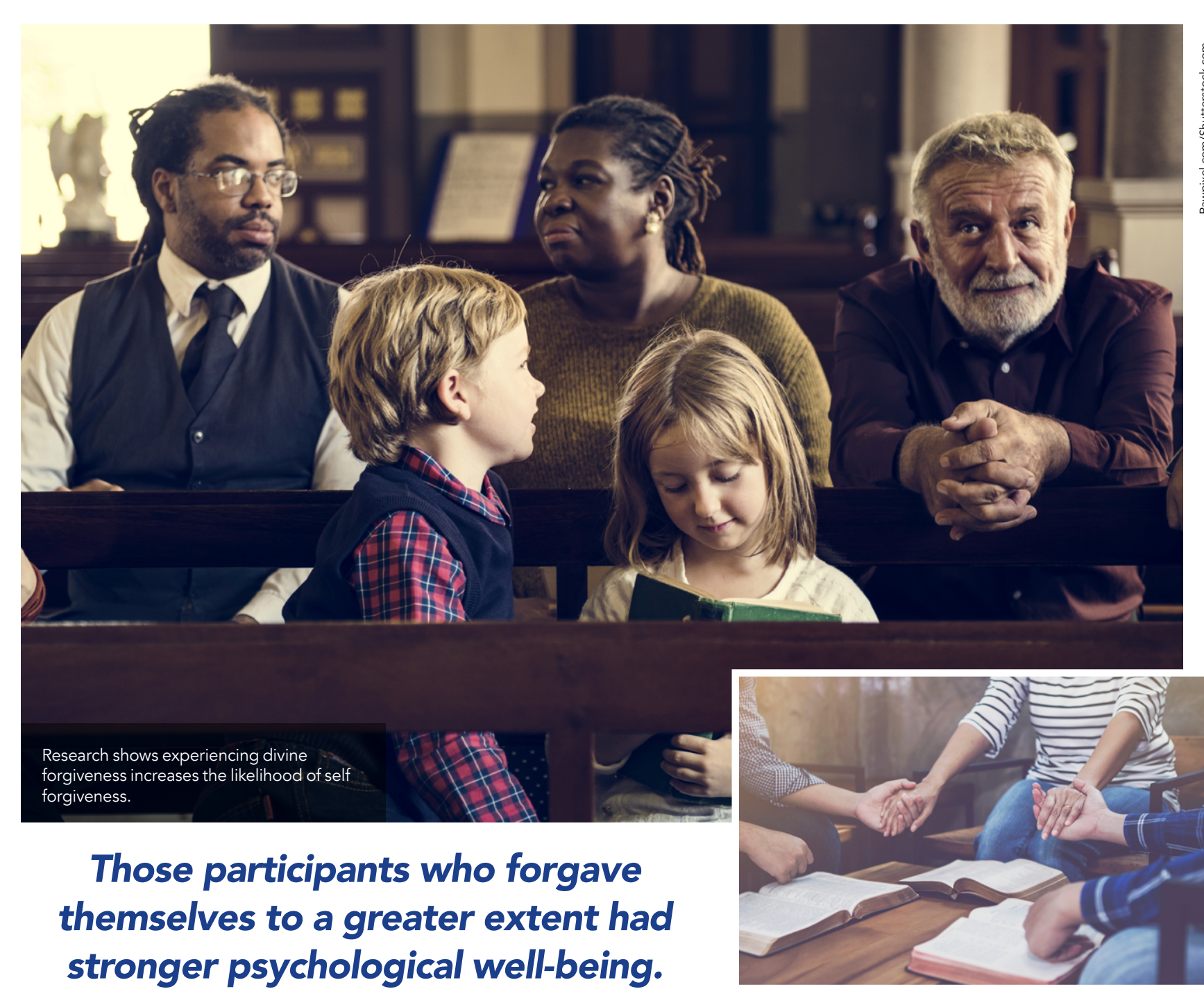

$\begin{array}{ll}\begin{array}{l}\text { used for measuring depressive symptoms } \\ \text { in nonclinical samples. }\end{array} & \begin{array}{l}\text { you?" was measured on a four-point } \\ \text { scale from "never" to "many times". }\end{array}\end{array}$

The self forgiveness measure was specifically developed for this study and for me to accept myself after have hur someone else" " "when I treat som hut wrongly I tend to think about it a lot", "even though it hurts when I let myself down, I quickly feel good about mysef again". Responses were given on a five-point scale from "strongly agree" to "strongly disagree".

Divine forgiveness was assessed with a scale that was also developed specifically for this study. The scale included items such as, "I am certain that God forgives me when l seek his forgiveness", whe I do something wrong, God is quick to forgive me ", which were measured on "stronint scale from "strongly agree" "strongly disagree". The last item, "how

Finally, religiosity was measured with two items: the frequency of attending religious point scale from "never" to "about once a day", and the selfreported importance of religion in a person's life measured from "not important" to "very important".

DIVINE FORGIVENESS IMPACTS DEPRESSIVE SYMPTOMS In this study, self forgiveness positively correlated with psychological well-being and negatively correlated with depressive symptoms. So those participants who forgave themselves to a greater extent had stronger psychological well-being, whereas those who displayed less self forgiveness were more likely to experien depressive symptoms. Similarly, divine forgiveness corlated positively with psychological well-being and negatively time, religiosity was significantly related to well-being, depressive symptoms

However, further analysis revealed that self forgiveness and divine forgiveness were significant predictors of improved psychological well-being and reduced depressive symptoms. These effects eligiosity Furthermon controlling for less likely to forgive themselves, a sense of divine forgiveness resulted in fewer negative symptoms. This is in contrast to participants who were more likely symptoms was less pronounced.

While these results indicate the importance of divine forgiveness for well-being and depressive symptoms limitations to the study. First, the Imitations to the study. First, the to forgive themselves, where the effect 
limited and likely reflected the cognitive encom the Second, the sample in this study was

restricted to undergraduate students, who

are emerging adults, and thus the results may not generalise to other age groups. Third, the sample was predominantly female, which may further restrict the generalisability of the findings.

\section{ANGRY GOD MAKES}

US LESS FORGIVING

In a separate study, the authors aimed

to further understand how religion affects

self forgiveness. Using a longitudinal

design, they examined how religious

activity and a sense of forgiveness by

God affect self forgiveness over time.

In parallel, the researchers designed an

Forgiveness-related publications

Peer review publications 2014-18

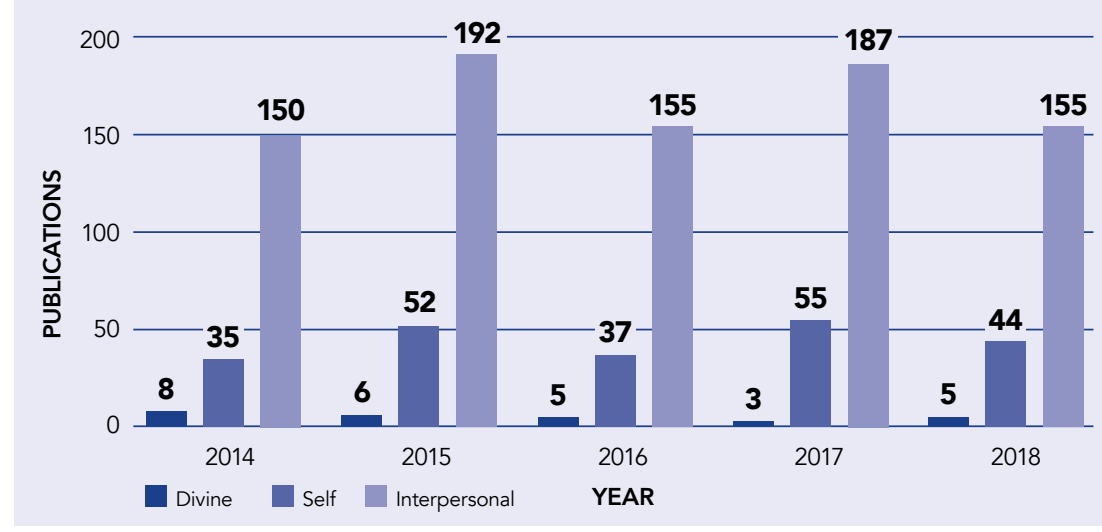

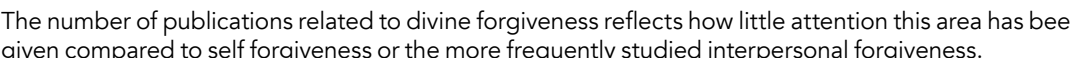

shown images of a penevolentgod

an angry god, or with non-religious

(abstract art) images before completing

questionnaires about their likely responses

to harm done to them by others and harm

done to them by themselves.

In the first part of the study, data

analysis revealed that perceived

forgiveness by God predicted later self

forgiveness, but self forgiveness did

not predict later divine forgiveness.

A similar pattern emerged for religious

activity. These results are consistent
with a causal relation in which divine

forgiveness and religious activity each increase self forgiveness.

In the second part of the study, the data showed that images of an angry god made respondents less likely to be self forgiving. Out of the three conditions, exposure to abstract art made respondents most likely to be self forgiving. One possible explanation is that an image of an angry god amplified the wrong described; it is a well-documented forgiveness. At the same time, it might be terivent

Experiencing divine forgiveness makes people more forgiving toward themselves.

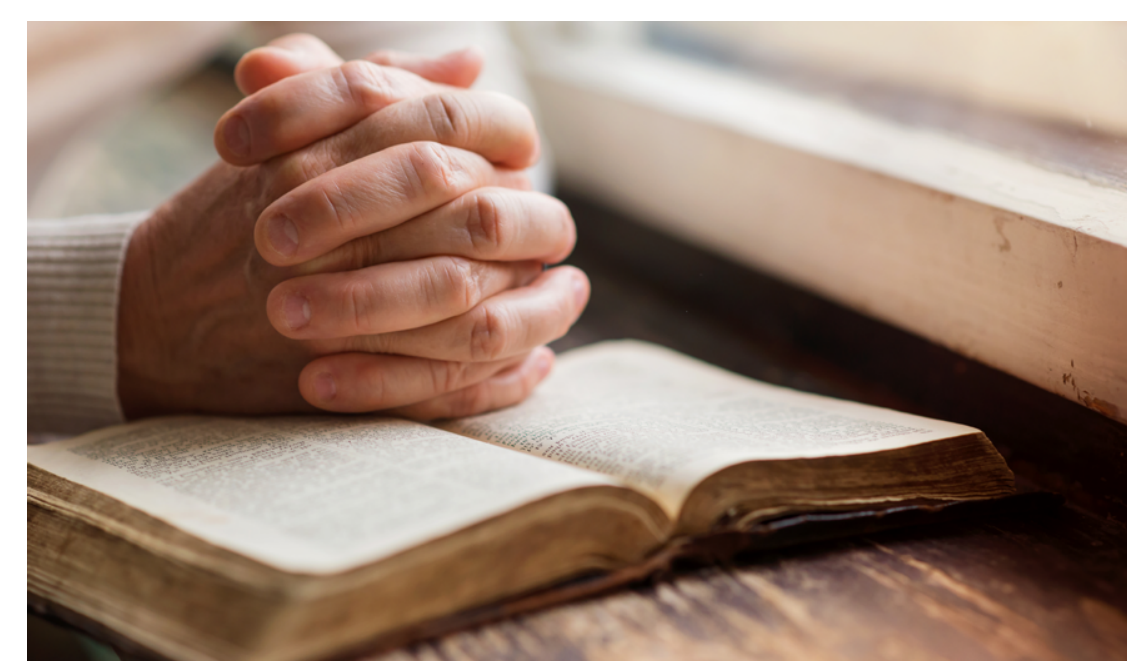

of negative emotions more pronounced, in turn, make people less likely to be forgiving of themselves.

THE IMPORTANCE

OF DIVINE FORGIVENESS

Dr Fincham and colleagues' research offers preliminary findings to support the view that experiencing divine orgiving toward themselves, which, in turn, translates to fewer depressive symptoms. These findings are potentially important for designing ventions aimed at improving men ealth for people of faith.

Outside of their practical applications these findings might be important for better understanding the human population identifies as religious - and for many, religion constitutes a core motivation to life - examining how eligious practices affect thoughts, beliefs and behaviours that are likely to determine health might be crucial.

On the way to understanding, scientists have to continue to engage with the key concepts and develop robust psychometric tests to measure relevant variables reliably. This is a difficult task, the pursuit of which can lead down many blind alleys. Nevertheless, it is a Worthwile endeavour that can bring us closer to describing divine forgiveness, fundamental to human life.

\section{Behind the Research}

\section{Professor Frank D. Fincham}

E: ffincham@fsu.edu T: +1 (850) 6444914 W: www.fincham.info

\section{Research Objectives}

Prof Fincham examines the importance of forgiveness for mental health and how divine forgiveness interacts with is aspect of well-being.

\section{Detail}

Professor Frank D. Fincham

225 Sandels

120 Convocation Way

FL 32306-149

USA

Bio

Frank $\mathrm{D}$. Fincham, PhD studies forgiveness and prayer in close relationships, including their impact on mental and physical health. A former Rhodes Scholar and Fellow of six different professional societies, his work has been recognised by numerous professional awards, including the President's Award, for "distinguished contributions to psychological knowledge"(British Psychological Society).

Funding

John Templeton Foundation

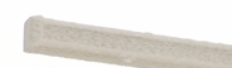

Collaborators

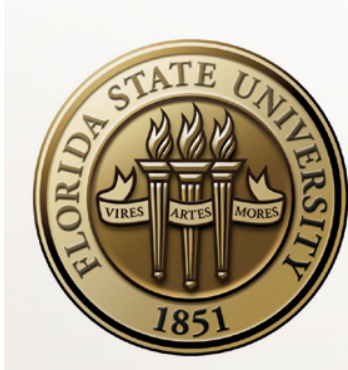

\section{References}

Fincham FD, May RW. (2019). Self-forgiveness and wellbeing: Does divine forgiveness matter? Journal of positive psychology. DOl: 10.1080/17439760.2019.1579361.

Fincham FD, May RW, Chavez FLC. (2019). Does being religious lead to greater self-forgiveness? Journal of positive psycholog, DO1: 101080/174397602019.1615109.

\section{Personal Response}

Your studies do not control for or discuss the differences between religions in their conceptualisations of God. differences on diving and self-forgiveness?

II All the world's longstanding religions emphasise divine oxpriens. Buill likely

adherents conceptualise God. Research on the mental representation of God consistently yields two broad. conceptions: a kindly or benevolent God and a wrathful or authoritarian God. For those who see God primarily as the former, the experience of feeling forgiven by God is as the latter it may be relatively rare. As suggested by earlier described studies, such differences are likely, in turn, to impact self-forgiveness. Our studies do not control for or discuss the differences between religions in their
conceptualisations of God.

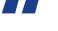

